\title{
Studying the Vulnerability of Steel Moment Resistant Frames Subjected to Progressive Collapse
}

\author{
Mojtaba Hosseini', Nader Fanaie ${ }^{2}$ and Amir Mohammad Yousefi ${ }^{1 *}$ \\ 'Department of Civil Engineering, Faculty of Engineering, Lorestan University, Lorestan, Iran; \\ hosseini.m@lu.ac.ir, amirmohammad.yousefi@yahoo.com \\ ${ }^{2}$ Civil Engineering Faculty, K.N. Toosi University of Technology, Tehran, Iran; fanaie@kntu.ac.ir
}

\begin{abstract}
The guidelines of Unified Facilities Criteria (UFC) and U. S. General Service Administration (GSA) provide the design requirements to reduce the potential of progressive collapse for structures. According to these codes, progressive collapses are occurred due to loss of a main vertical structural element. In this study, the vulnerability of an official 10-story steel moment resistant frame, designed according to Iranian National Building Codes (INBC) is assessed. The following nonlinear dynamic analysis procedure is recommended by the UFC 4-023-03 guideline, which provides technical guidance for mitigation and protection of progressive collapse. Alternate Path (AP) method has been applied to evaluate the structure that can bridge over notionally removed column and nonlinear dynamic analysis procedure conducted. The investigated cases emphasize on the removal of a corner column in the ground floor, fifth floor, eighth floor, and just below the roof floor. Based on the results obtained in this research, steel moment resistant frames, designed according to Iranian National Building Codes, do not satisfy UFC acceptance criteria and have high potential for progressive collapse in corner column removal scenarios. Therefore some modifications have been conducted on the codes to satisfy the UFC limits.
\end{abstract}

Keywords: Alternate Path Method, Nonlinear Dynamic Analysis, Steel Structure

\section{Introduction}

In general, a structure collapses progressively when one of its vital members fails causing the failure and damage of adjoining elements. As a result, these can lead to finally total or partial collapse of the structure. In building structures progressive collapse often start with omitting vertical members like columns. The failure of main vertical members might happen due to abnormal and extreme loadings such as earthquake, gas explosion, fire and accidental impact of a vehicle. If the building cannot resist because of inadequate continuity, ductility and redundancy, it collapses and may cause considerable casualties. Several progressive collapses occurred incidentally in the last decades. The most important one was Ronan Point apartment, a 22-story building in the East of London, occurred in 1968. The apartment started to collapse progressively because of an accidental gas explosion occurred on its mid-height in a corner. This event motivated the engineers and academic researchers to research comprehensively and develops the acceptable design criteria for preventing or reducing progressive collapse of structures. Two important guidelines have been posed and developed recently. General Service Administration $(\mathrm{GSA})^{1}$ and the Unified Facilities Criteria $(\mathrm{UFC})^{2}$ which address and explain the design requirements of progressive collapse for new and existing constructions based on different categories. The UFC regulations change almost annually for revising and publishing the updated guidelines. It presents two design approaches, indirect and direct, for preventing and reducing the progressive collapse. Regarding the former, called Tie Force method (TF), the engineers use ties or new systems to keep the elements of structure joined and enhance the ductility,

*Author for correspondence 
redundancy and continuity in an extreme or abnormal loading. The latter consists of Specific Local Resistance (SLR) and the Alternative Path (AP) methods. SLR method provides adequate local strength of structure to resist against certain load or condition. In the AP method the damage of structure is localized by its capability to bridging over the missed elements.

In this paper, the effective measures are considered to evaluate progressive collapse vulnerability of structures. For this purpose an official 10-story steel moment resistant frame with specific administrative application designed according to Iranian National Building Codes and with a focus on requirements of Iranian Seismic Code No. 2800 for satisfying UFC regulations. AP method has been applied according to the selected Occupancy Categories (OC) presented in Tables (2-1) and (2-2) from UFC 2 .

Nonlinear dynamic analyses are conducted on some scenarios after sudden removal of vertical load-bearing members using AP method.

Many researchers have studied and evaluated progressive collapse using AP method. The most important researches, conducted on the case, are as follows:

Tsai and Huang ${ }^{3}$ have investigated the effects of three types of exterior infill walls on the performance and response of a reinforced concrete building subjected to some column removal. He found that the progressive collapse resistance of the buildings subjected to column loss increase notably by wing-type walls and the deformation capacity decreases by exterior non-structural walls.

Sasani et al. $^{4}$ studied, analytically and experimentally, progressive collapse potential and resistance of the 11-story RC Crown Plaza Hotel in Houston, subjected to strict initial damage. According to them, it is important to model yielding strength and axial stiffness of floor elements accurately, as they affect partially the in-plane floor performance. They concluded that yielding stress or beam cracking has not significant effect on the structural deformation, regarding analysis methods.

Shi et al. ${ }^{5}$ proposed a new procedure for progressive collapse of RC frames under blast and extraordinary loading by determining initial damage of structural elements. He compared the numerical results with those obtained by AP method for proposing his method. As the presented method needs no comprehensive model, it significantly decreases the computational time. The method was compared with GSA guidelines nonlinear dynamic procedure and showed better foresight to the progressive collapse and faced less trouble in considering the initial damage of structural elements.
Sasani and Sagiroglu ${ }^{6}$ evaluated the progressive collapse potential of a 6-story RC structure, San Diego Hotel, by sudden removal of two exterior columns, one of which was at the corner. According to the experimental results, the joint above an omitted column moved similarly in its two underneath floors. However, the above floor experienced insignificant smaller deformation due to the loss of axial force of the column. The reason of smaller deformation was loss of the column axial force that connected to two floors and its corresponding elongation.

Graham $^{7}$ found that static analysis using AP method is simpler and more conservative in comparison with dynamic analysis. Despite being harder and more complicated, dynamic analysis is more accurate.

Hansen et al. $^{8}$ investigated the performance of external columns of reinforced concrete buildings in tridimensional models. They used nonlinear dynamic analysis to control the edge beams by removing the external column. The results of their study showed that nonlinear dynamic analysis is important in the investigation of progressive collapse and gaining accurate and realistic structural response.

Marjanishvili and Agnew ${ }^{9}$ applied linear-dynamic, linear-static, nonlinear-dynamic and nonlinear static analyses for studying the progressive collapse based on the U. S. General Service Administration (GSA, 2003). According to the authors the GSA acceptance criteria were not conservative for linear analysis methods as both linear-static and linear-dynamic analyses create maximum deformations.

Marchand and and Alfawakhiri ${ }^{10}$ conducted a comprehensive inquiry on the analysis and design methods for mitigating the effects of blast and progressive collapses. He has discussed the performance, expected in GSA provisions. He developed the guidelines of UFC and GSA in his research.

Kim and $\mathrm{Kim}^{11}$ investigated the resistance capacity of steel frames for progressive collapse using AP methods based on UFC and GSA guidelines. They compared nonlinear dynamic analysis with linear static procedure. According to these researchers, the progressive collapse potential was high when a corner column was suddenly removed. Moreover, in case of increasing in the number of stories, the progressive collapse potential increases, but the resistance capacity decreases.

Helmy et al. ${ }^{12}$ evaluated the resistance capacity of a 10-story typical RC framed slab structure, designed based on ACI 318-08 provisions, for progressive collapse concerning the removal of wall and column. 


\section{The Designed Steel Building}

\subsection{Structural Details}

In this study, a 10-story official structural building is investigated. The height of all stories is $3.2 \mathrm{~m}$. Its first story is an open space for public. As shown in Figure 1, the structure has no irregularities in its elevation or plan. All floors are $5 \times 5$ panels, each of which $5 \times 5 \mathrm{~m}$. They have $625 \mathrm{~m}^{2}$ in sum with $25 \mathrm{~m}^{2}$ areas at corner panels. This building has intermediate steel moment-resistant frame in both sides. It has been designed according to the Iranian Seismic Code No. $2800{ }^{13}$ and Iranian National Building Codes ${ }^{14,15}$.

The column sections used for the stories $1-4,5-7$ and $8-10$ are Box $340 \times 340 \times 30$, Box $250 \times 250 \times 20$ and Box $200 \times 200 \times 25$, respectively, Table 1 . The beam sections applied for the stories 1-4, 5-7 and 8-9 and roof story are IPE400, IPE360, IPE330 and IPE300, respectively, Table 1.

\subsection{Material Properties and Loading}

The materials used for the structure are based on Iranian National Building Codes part $10^{15}$. The compressive strength $\left(f_{c}\right)$, used for concrete in all floors, is $25 \mathrm{MPa}$ and tabulated in Table 2. The design yield strength and ultimate strength values are 240 and $400 \mathrm{MPa}$ for beams and columns. The elasticity modules of steel and concrete

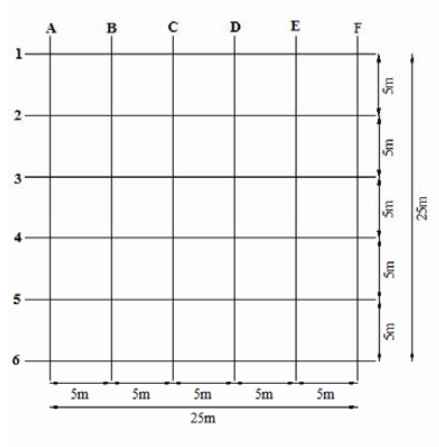

Plane view

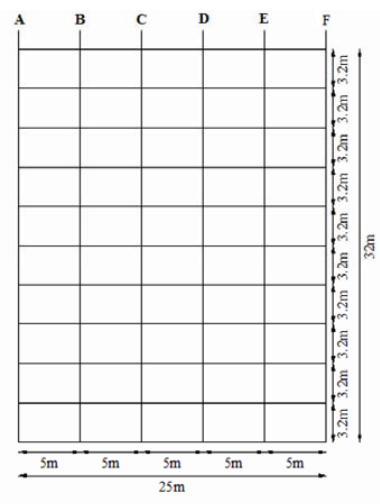

Elevation view
Figure 1. Elevation and plane of the designed structure. are $200000 \mathrm{MPa}$ and $20000 \mathrm{MPa}$, respectively. Based on INBC part $6^{14}$, a Live Load (LL) of $1.47 \mathrm{KN} / \mathrm{m}^{2}$ is applied to the roof and $2.45 \mathrm{KN} / \mathrm{m}^{2}$ to other floors. In addition to the self-weight of structural elements, the Dead Loads (DL) of $4.41 \mathrm{KN} / \mathrm{m}^{2}$ and $5.4 \mathrm{KN} / \mathrm{m}^{2}$ are considered for the roof and all other floors, respectively. Furthermore, the perimeter wall weights of $3.04 \mathrm{KN} / \mathrm{m}$ and $5.88 \mathrm{KN} / \mathrm{m}$ are applied to the roof and other floors, respectively.

\section{Analyzing and Modeling the Progressive Collapse}

There are three procedures in the UFC for analyzing the structures prone to progressive collapse: 1) Linear Static Procedure (LSP), the simplest one, is commonly used in the structural analysis and design. The material is assumed linear elastic; there is no geometric nonlinearity; and the structure has small deformations. 2) Nonlinear Static Procedure (NSP), in which both geometric and material nonlinearities are considered. 3) Nonlinear Dynamic Procedure (NDP) has been more used by the researchers. It is more accurate and realistic comparing to others. Besides, it considers both geometric and material nonlinear behaviors. The structure is subjected to dynamic loads and can experience large deformation without any restriction for irregularities in elevation or plan. Nonlinear dynamic analysis seems more appropriate for analyzing progressive collapse phenomenon as it expresses the nonlinearity and dynamic phases. Therefore, the mentioned procedure has been applied for analyzing the structure.

Table 1. The dimensions of structural members $(\mathrm{mm})$

\begin{tabular}{lccc}
\hline \multicolumn{2}{c}{ Beam Members } & \multicolumn{2}{c}{ Column Members } \\
\hline Story & $5 \mathrm{~m}$ & Story & $3.2 \mathrm{~m}$ \\
$1-4$ & IPE400 & $1-4$ & Box340 $\times 340 \times 30$ \\
$5-7$ & IPE360 & $5-7$ & Box $250 \times 250 \times 20$ \\
$8-9$ & IPE330 & $8-10$ & Box200 × 200×25 \\
10 & IPE300 & - & - \\
\hline
\end{tabular}

Table 2. Material properties

\begin{tabular}{lccccc}
\hline Material & Poisson's ratio & Young's modulus (MPa) & $\begin{array}{c}\text { Compressive } \\
\text { strength (MPa) }\end{array}$ & Yield stress (MPa) & Ultimate strength (MPa) \\
\hline Steel & 0.3 & 200,000 & - & 240 & 400 \\
Concrete & 0.15 & 20,000 & 25 & - & - \\
\hline
\end{tabular}




\subsection{Load Combination}

The following gravity load combination $\left(\mathrm{G}_{\mathrm{ND}}\right)$ has been applied to the entire structure based on UFC guidelines:

$$
G_{N D}=1.2 D L+0.5 L L
$$

where, $L L$ and $D L$ are live load and dead load, respectively.

In addition to gravity loads, the lateral loads $\left(\mathrm{L}_{\mathrm{LAT}}\right)$ should be applied to the structure sides as follows:

$$
L_{L A T}=0.002 \sum P
$$

Where, $\sum P$ is sum of the gravity loads applied on each floors and substituted for wind load.

It should be noted that four separate analyses should be conducted on the structure. In the other words, lateral loads should be applied to each sides of the buildingsouth to north, north to south, east to west and west to east. Helmy et al. ${ }^{12}$ investigated the influences of lateral load directions. Apart from these effects, they considered the same direction that has been used in this study for lateral load. This direction leads to the largest deflection in the structure.

\subsection{Applied Loads and Loading Procedure}

The internal forces acting on the corner column is computed in order to perform nonlinear dynamic analysis. The corner column is removed and its equivalent forces are applied to the connection of the removed column. The equivalent internal forces are $\mathrm{M}, \mathrm{P}$ and $\mathrm{V}$, defined as bending moment, axial force and shear force. The variables $\mathrm{G}_{\mathrm{ND}}$ and $\mathrm{L}_{\mathrm{LAT}}$ denote gravity loads and lateral loads. According to Figure $2^{17}$, the equivalent internal forces started from zero sec. and increased linearly up to five sec. for simulating the dynamic effect of column removal phenomenon. The internal forces are kept constant until the $7^{\text {th }}$ second after they met their full capacity and met their full capacities and the system reaches its stable condition. Then, arriving to $7^{\text {th }}$ second, the internal forces are removed suddenly ${ }^{11}$.

\subsection{Column Removal Scenario}

In the alternative load path method, the UFC guidelines refer to several cases for removing the structural elements and analyze the structure subjected to progressive collapse. Accordingly, four element removal cases, mentioned below, should be considered for removing the elements in the elevation and plan of a structure and performing AP analyses.
1. the first story above ground floor

2. the story below the roof

3. the story at mid-height of the structure

4. the story above the location of change in column section.

Therefore, corner columns have been removed in order to investigate the effects of the column removal of the building, based on the mentioned statements. The locations of removed corner columns in the studied tenstory building are as follow:

1. the first story, above the grade

2. the fifth story, at mid-height of the building where the column sections is changed

3. the eighth floor, where the column sections is changed

4. the ninth story, the story below the roof.

Figure 3 shows the locations of removed columns in the elevation and plan. A-1 (intersection of axes $\mathrm{C}$ and 1 ) columns as representative of corner columns are notionally removed in the height of the structure one at a time in stories in distinct analyses.

\subsection{Analytical Modeling}

OpenSees program code has been used for 2-D modeling and numerical analysis of the exterior frame ${ }^{16}$. It is powerful nonlinear software for simulating the applications in the earthquakes as well as structural engineering using finite element methods. 2-D nonlinear dynamic procedure

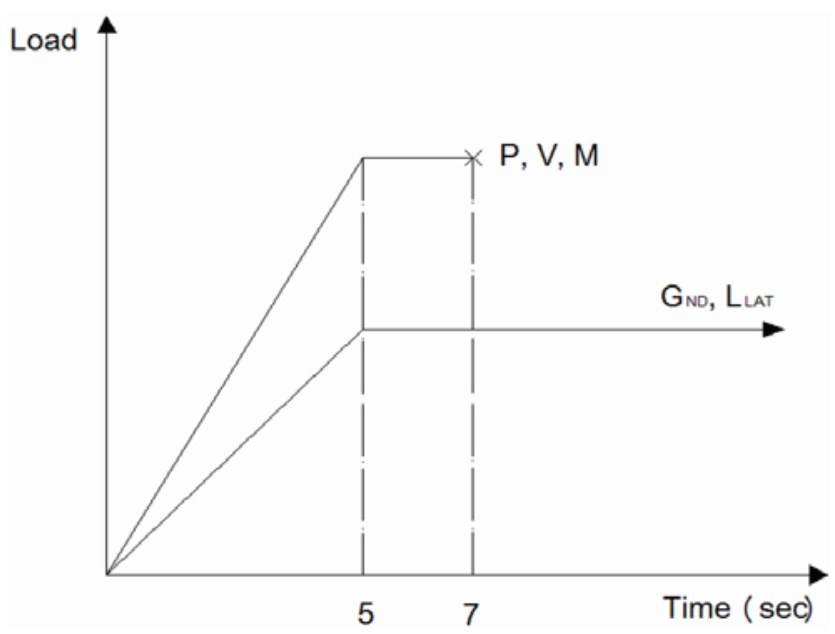

Figure 2. Applying dynamic loads for nonlinear dynamic procedure. 
has been performed for each analysis in order to analyze the structure. Beams and Columns have been presented by nonlinear beam-column element having Steel02 hysteretic material model (Giuffre-Mento-Pinto model with isotropic strain hardening ${ }^{16}$. The post-yield stiffness of members is considered to be $2 \%$ of the initial stiffness. The values of controlling the transition from elastic to plastic branches- $\mathrm{R}_{0}, \mathrm{R}_{1}$ and $\mathrm{R}_{2}$ are assumed as $15,0.925$ and 0.15 , respectively. The material and hysteric behavior of model with isotropic hardening in tension and compression are shown in Figure 4. Due to the possibility of large deformations, the common damping ratio which usually applies to the structures is considered as $5 \%$ of the critical damping. The progressive collapse analyses are conducted by removing a column in height of the building based on UFC 2013 guidelines.

\section{Analysis Results and Discussion}

This study is to determine the effects of removing corner columns on axial forces of adjacent columns. For this purpose, 2-D nonlinear dynamic analysis has been conducted on the exterior frame of structure to assess the mentioned effects on the height of structure. One of the most important effects of the column removal phenomenon on other columns is that, the forces in the adjacent columns are considerably changed. In the other words, by removing a column, the adjacent columns impose significantly the stresses and forces. This might be due to the removing of vertical load bearing member and transferring the weight

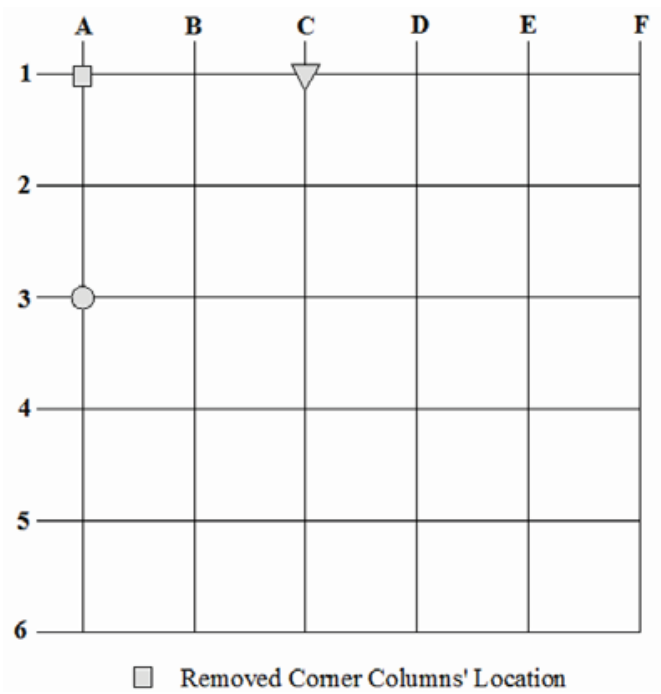

Figure 3. Notionally removed corner column for AP analysis.

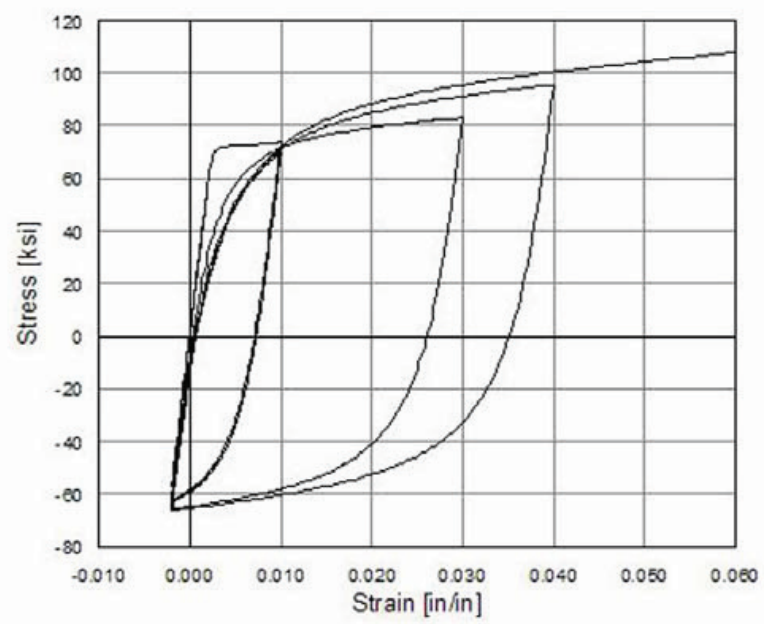

a. Hysteretic behavior of model with isotropic hardening in tension.

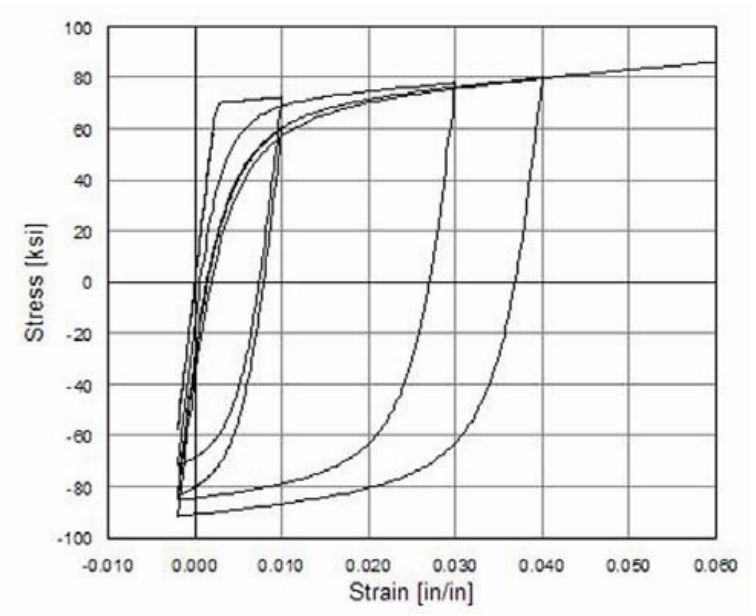

b. Hysteretic behavior of model with isotropic hardening in compression.

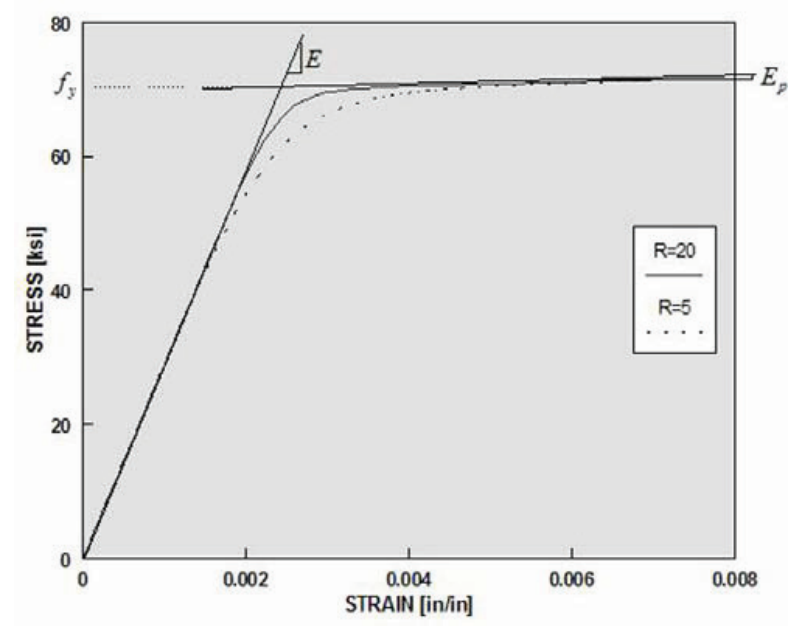

c. Material Parameters of Monotonic Envelope.

Figure 4. The constructive material of the models. 
of the elements to other adjacent columns. These extra forces imposed on columns should be assessed to know whether or not the structure can bridge over the notionally removed corner column. Accordingly, four cases have been analyzed to investigate extra column axial forces imposed on adjacent columns. The simulation results, obtained from analyses, are presented in the following.

\section{1 $\mathrm{A}_{1}$ Corner Column Removal in the First Story}

After removing the $\mathrm{A}_{1}$ corner column in the first story, the axial compressive forces have increased significantly in the adjoining columns of the steel structure. Figure 5 shows the time history of the axial forces at the adjacent columns, obtained from progressive collapse nonlinear dynamic analysis.

The compressive axial forces of $\mathrm{B}_{1}, \mathrm{C}_{1}, \mathrm{D}_{1}, \mathrm{E}_{1}$ and $\mathrm{F}_{1}$ columns, computed from primary analysis, were 1454.9, $1476.83,1476.81,1454.2$, and $720.41 \mathrm{KN}$, respectively, before progressive collapse analysis. The support lost and the compressive axial forces, obtained from structural analysis for $\mathrm{B}_{1}, \mathrm{C}_{1}, \mathrm{D}_{1}, \mathrm{E}_{1}$ and $\mathrm{F}_{1}$ columns, were 12827 , 7305.24, 7313.5, 7289.7 and $3753.87 \mathrm{KN}$, respectively. According to the gained results, the compressive axial forces in the adjoining column of $\mathrm{B}_{1}$ increased 8.8 times the primary forces and in other columns 5.21 times.

\section{2 $\mathrm{A}_{1}$ Corner Column Removal in the Fifth Story}

In this case, by removing $A_{1}$ corner column in the fifth story, in the mid-height of the structure, the axial loads increase in adjacent columns, Figure 6.

The compressive axial forces of $\mathrm{B}_{1}, \mathrm{C}_{1}, \mathrm{D}_{1}, \mathrm{E}_{1}$ and $\mathrm{F}_{1}$ columns, computed from primary analysis, were 841.24 , $855.53,855.52,840.19$, and $410.91 \mathrm{KN}$, respectively, before progressive collapse analysis. After removing the corner column of the fifth story, the compressive axial forces obtained from structural analysis, were 7272.52, 4218.26, 4229.83, 4221.72 and $2130.7 \mathrm{KN}$, respectively. Therefore, the compressive axial forces in $\mathrm{B}_{1}$ column increased 8.6 times the primary forces and 5.18 times other columns.

\section{3 $\mathrm{A}_{1}$ Corner Column Removal in the Eighth Story}

In this case, after removing the A1 corner column in the eighth story, where the sections of the columns are changed, the axial loads in adjacent columns increased but not like the last cases. In the last cases the increasing forces were significant. The obtained results are presented in Figure 7.

The compressive axial forces of the columns $B_{1}, C_{1}, D_{1}$, $\mathrm{E}_{1}$ and $\mathrm{F}_{1}$, computed from primary analysis, were 398.4, 404.3, 254.5, 398.35, and 193.1 KN, respectively, before progressive collapse analysis. After the corner column lost, the compressive axial forces, obtained from structural analysis, were 3456.8, 1998.6, 2012.87, 2007 and $1004.1 \mathrm{KN}$, respectively. Therefore, the compressive axial forces in the adjoining column of $\mathrm{B}_{1}$ increased 8.67 times the primary forces and 5.19 in the other columns.

\section{4 $\mathrm{A}_{1}$ Corner Column Removal in the Ninth Story}

Regarding the Al corner column removal in the ninth story, the compressive axial forces in adjacent columns have increased after removing that column. The analysis results have shown in Figure 8.

The compressive axial forces of $\mathrm{B}_{1}, \mathrm{C}_{1}, \mathrm{D}_{1}, \mathrm{E}_{1}$ and $\mathrm{F}_{1}$ columns, computed from primary analysis were 250.7, $254.55,254.5,250.7$, and $121.72 \mathrm{KN}$, respectively, before progressive collapse analysis. The corner column has been removed in ninth story. The compressive axial forces, obtained from structural analysis, were 2172.8, 1263.5, $1273.9,1267.12$ and $636.6 \mathrm{KN}$, respectively. The compressive axial forces in the adjoining column of $B_{1}$ increased 8.66 times the primary forces and 5.23 times in the other columns.

Based on Iranian National Building Code part 10, the ultimate axial strength have been calculated for all columns in four scenarios and tabulated in Table 3.

In order to assess the vulnerability of the structure against progressive collapse phenomenon, the column buckling and local web buckling or local flange buckling have been investigated. The results obtained from analyses have been compared with those of the criteria mentioned in that code. Regarding the analyzed scenarios, the adjacent $B_{1}$ columns in first (above the ground) and fifth stories (at the mid-height of the structure where the column sections are changed) do not satisfy the INBC limits. In case of $A_{1}$ corner column removal, the axial forces of $\mathrm{B} 1$ columns are $30 \%$ and $40 \%$ greater than the ultimate strengths in the first and fifth stories, respectively. This is explained by the fact that, when the corner columns removed, the weight of the structural elements tolerated by removed columns, are transferred to other columns especially to the nearest ones. This leads to increase pressure and buckle the columns. 


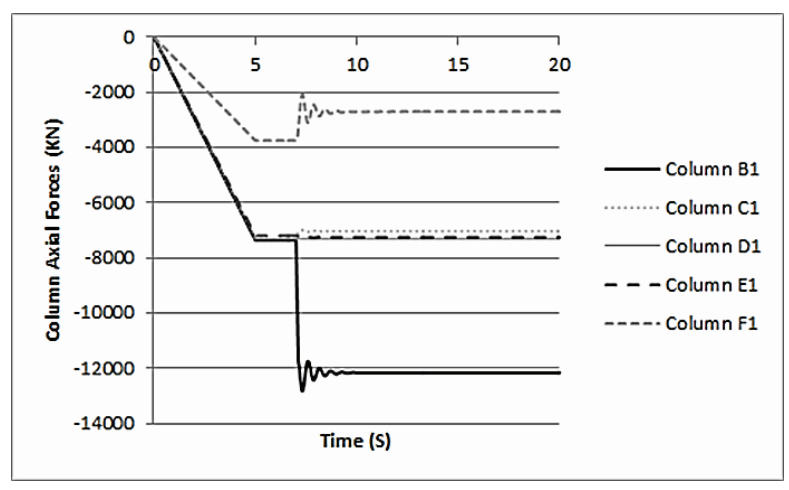

Figure 5. Time history of axial forces at the adjacent columns in the first floor.

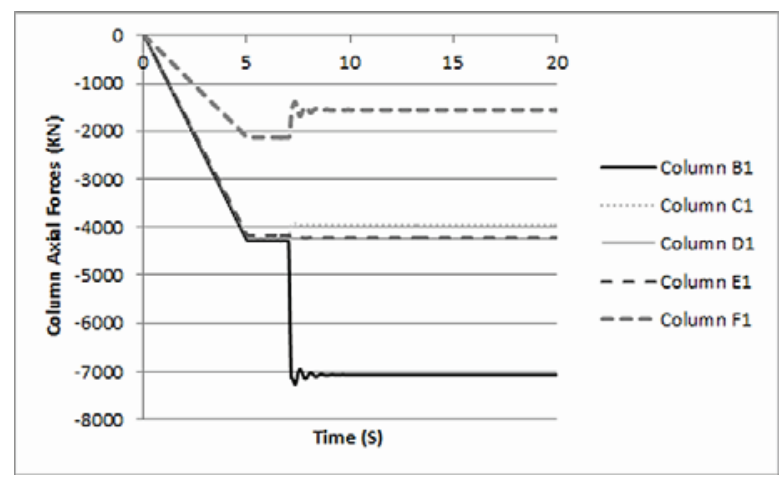

Figure 6. Column axial history of adjacent columns in the fifth floor.

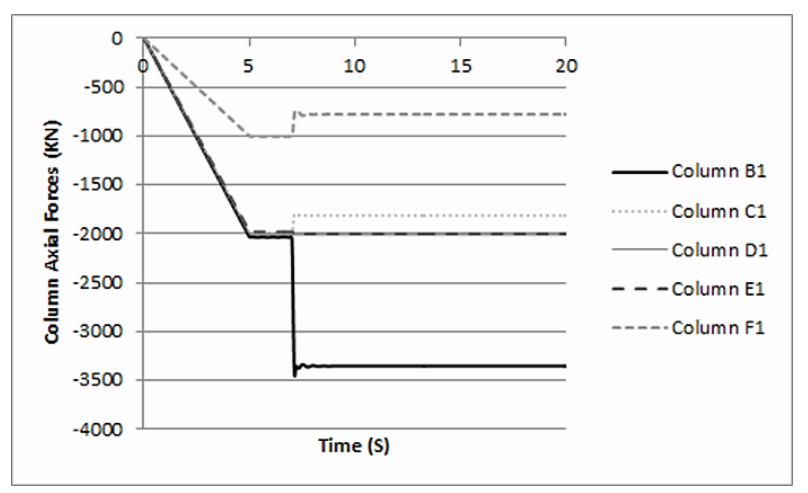

Figure 7. Time history of axial forces at the adjacent columns in the eighth floor.

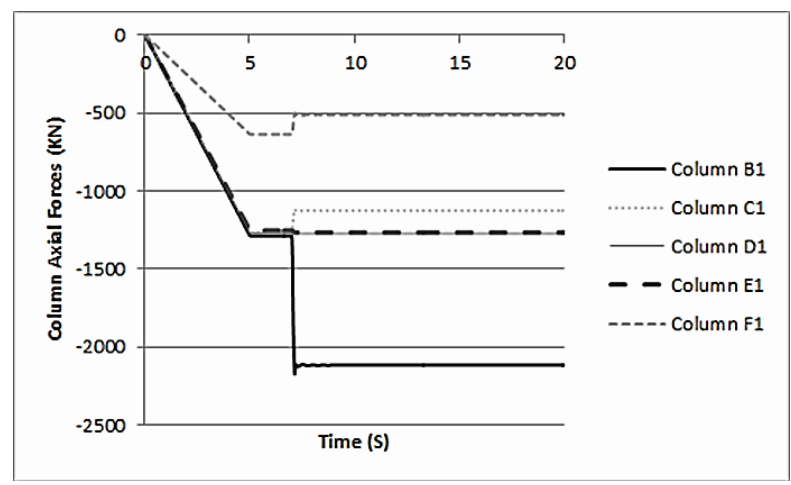

Figure 8. Column axial history of adjacent columns in the ninth floor.

Table 3. Ultimate capacity of the column

\begin{tabular}{lcc}
\hline Story & Column Members & Ultimate Capacity $(\mathrm{KN})$ \\
\hline $1-4$ & Box340 $\times 340 \times 30$ & 8887.8 \\
$5-7$ & Box $250 \times 250 \times 20$ & 4333.4 \\
$8-10$ & Box $200 \times 200 \times 25$ & 4068.9 \\
\hline
\end{tabular}

\section{Summary and Conclusion}

This study assesses the vulnerability of steel moment resistant frames designed according to the regulations of Iranian National Building Codes for design and construction of steel structures, with respecting the guidelines of UFC regulations for alternative path method. The analytical results, obtained in this research are summarized as follows:

- In case of corner column removal in first and fifth story, the adjacent columns, especially the nearest to the removed member cannot tolerate the pressure created by the weight of the structural members. These extraforces are more than ultimate capacity calculated for these columns which lead to buckle the columns and finally progressively collapse the structure.

- The steel moment resistant structure designed according to the Iranian National Building Codes and Iranian Seismic Code No. 2800 does not satisfy the UFC code limit.

- The axial force values of adjoining columns are $30 \%$ and $40 \%$ greater than their ultimate strengths in the corner column removal of the first and fifth stories, respectively. Therefore, some modifications have been needed to increase the capacity of these columns (45\%) and progress the safety margin. This can be achieved by increasing column dimensions or using new materials and methods. 


\section{References}

1. U. S. General Services Administration (GSA). Progressive collapse analysis and design guidelines for new federal office buildings and major modernization projects. Washington, DC; 2003.

2. U. S. Department of Defense. Design of building to resist progressive collapse UFC 4-023-03. Washington, DC; 2013.

3. Tsai M-H, Huang T-C. (2011). Progressive collapse analysis of an RC building with exterior non-structural walls. Procedia Engineering. 2011; 14: 377-84.

4. Sasani M, Kazemi A, Sagiroglu S, Forest S. Progressive collapse resistance of an actual 11-story structure subjected to severe initial damage. J Struct Eng. 2011; 137(9):893-902.

5. Shi Y, Li Z-X, Hao H. A new method for progressive collapse analysis of RC frames under blast loading. Eng Struct. 2010; 32(6):1691-703.

6. Sasani M, Sagiroglu S. Progressive collapse resistance of hotel San Diego. J Struct Eng. 2008; 134(3):478-88.

7. Graham P. Progressive Collapse: Case studies Using Nonlinear Analysis, Structures Congress 2005, American Society of Civil Engineers; 2005.

8. Hansen E, Wong F, Lawver D, Oneto R, Tennant D, Ettouney M. Development of an analytical database to support a fast running progressive collapse assessment tool. Structures Congress 200. 2005. p. 1-14.
9. Marjanishvili S, Agnew E. Comparison of various procedures for progressive collapse analysis, Journal of Performance of Constructed Facilities. 2006; 20(4): 365-74.

10. Marchand KA, Alfawakhiri F. Facts for steel buildings number 2: Blast and progressive collapse. American Institute of Steel Construction: Chicago (IL); 2005.

11. Kim J, Kim T. Assessment of progressive collapse-resisting capacity of steel moment frames. Journal of Constructional Steel Research. 2009; 65(1):169-79.

12. Helmy H, Salem H, Mourad S. Progressive collapse assessment of framed reinforced concrete structures according to UFC guidelines for alternative path method. Eng Struct. 2012; 42:127-41.

13. Iranian code of practice for seismic resistant design of buildings. Standard no. 2800. 3rd ed. Building and Housing Research Center; 2004.

14. Iranaian National Building Codes For Structural Design, Part 6. Minimum Design Loads for Buildings; 2008.

15. Iranaian National Building Codes For Structural Design, Part 10. Design of Steel Buildings; 2008.

16. Mazzoni S, McKenna F, Scott MH, Fenves GL et al. OpenSees command language manual; 2007.

17. Yousefi AM. Investigation on progressive collapse of steel moment resistant frame buildings [Master of Science Dissertation]. Lorestan University; 2014. 